\title{
The concept for e-material creating and formatting application prototype
}

\author{
Kristine Mackare ${ }^{1}$, Anita Jansone ${ }^{1}$ \\ ${ }^{1}$ Faculty of Science and Engineering, Liepaja University
}

\section{Article Info}

Received Nov $1^{\text {st }}, 2018$

\section{Keyword:}

Application prototype

Concept

E-material formatting

Screen-reading

User-centric design

\begin{abstract}
Smart technologies and screen use increase, especially for screen-reading and its use in educational reasons. It is helpful and up to date for nowadays people. But perception from the screen is different comparing to perception of printed materials. Technologies development is faster than people adaptation to the new conditions. According to research, it brings up some different problems, especially in vision and ocular health, that affect people life quality and can increase problems in the future. There is a need for the solution. It is believed, well-formatted e-materials could improve users reading comfort and vision health, that can be followed by educational and life quality increase. One of the possible solutions is the e-material formatting application. That can improve the comfort of using e-material in learning and study process and decrease near workload. And the goal could be reached by adapting text formatting for individual needs in addition. Formatting recommendations would be based on user habits research, vision conditions, symptoms and refraction changes research from practice, and on developed recommendations for user-centric and adaptive educational e-material creation and formatting. In this paper, the detailed concept for the application prototype is shown.
\end{abstract}

\section{Corresponding Author:}

Kristine Mackare,

Faculty of Science and Engineering,

Liepaja University,

Liela iela 14, Liepaja, LV-3401, Latvia

Email: kristine.mackare@gmail.com

\section{Introduction}

Near work is the work that involves focusing your eyes on a nearby object as the activities done at a short working distance, such as reading, studying (doing homework, writing), computer use, playing video games, or watching TV, etc. all at distance closer than $2 \mathrm{~m}$. [1;2;3;4] A big near-work load is a near work for a prolonged period of time. [5] Due to the high visual demands of all near work, especially viewing texts and images, reading, learning both print media and computer screen, are making effects on vision. $[2 ; 6 ; 7 ; 8] \mathrm{It}$ has been considered to be a potential cause to myopia development what is one of the biggest nowadays problems. [9; 10]

All digital devices are a big part of every person's life in the nowadays technological era. The smart devices use increase as everybody finds them useful on a daily base for solving different problems and spending free time. According to statistical data, at least $51 \%$ worldwide population uses the internet and digital devices to provide it. [11] That increase near workload and effect on eyes and vision system.

As it is known, reading from printed materials and screen is different. Reading research shown that screen reading is much difficulty [12] and readers need to use different reading model. [13] People vision system is adapting for the new visual information perception model, but the human evaluation process isn't as fast as technology progress. The visual system needs help. There are no possibilities to stop the development of 
devices, and it would not be useful or wise, but there is a need to try to help achieve a more comfortable and healthier screen reading.

There is a need for user-centric and adaptive educational e-materials. Users intuitive ask for the more individual approach for screen work what is related to objective findings. Formatting to e-materials should be applied for natural and comfortable perception and in cooperation with visual processes. In addition, they should be helping the learning process and facilitating memorisation.

\section{The concept of application}

The concept for application prototype has been made based on previously developed recommendations for ematerial format-ting what is based on user preference research and oriented on users' individual factors and need.

The application idea involves such components as an idea of the tool by itself - what it must do and how to do that, information must contain in the database -, and vision of tool design. It must give a clear understanding of the application to the programmer what must be done.

The app must work not only for app creator but also for both e-material creators and e-material users. In addition, the app should provide feedback information for researchers.

\subsection{The short concept of application}

The main idea of the concept is simply represented by a sequence diagram in Fig.1.

It represents three mine edges of the app: user, interface and database. It includes collaboration processes between edges and the mine idea of the app - text formatting of documents based on user groups.

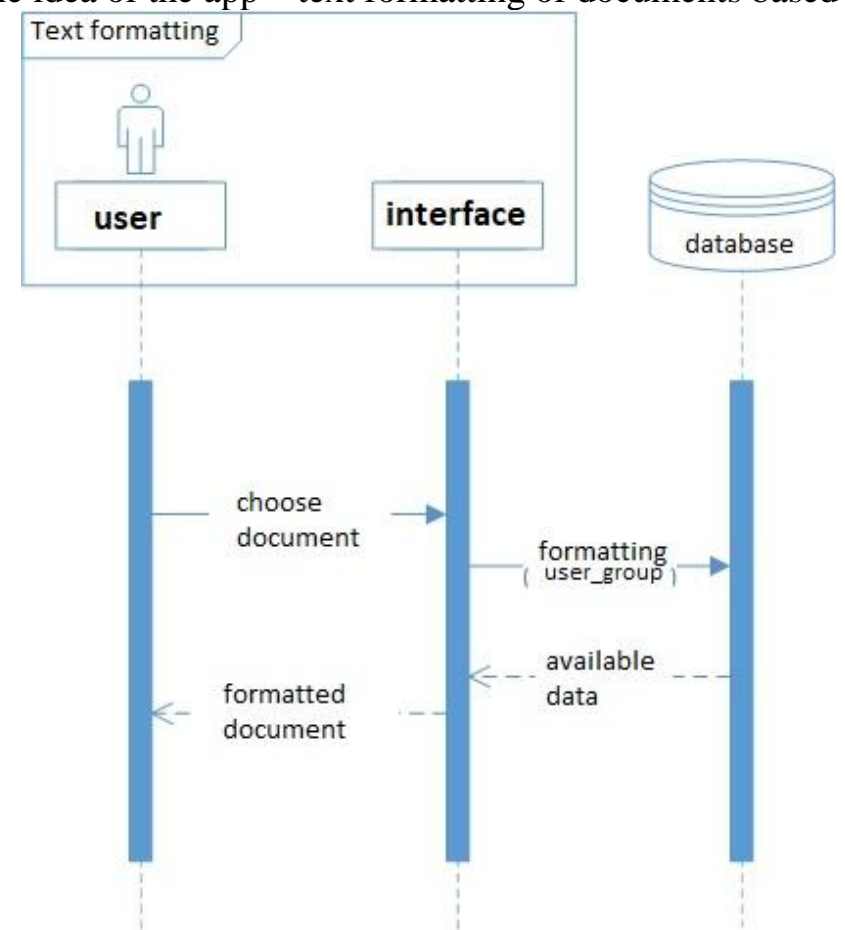

Figure 1. Sequence Diagram for short and simple application concept. [14]

\subsection{The concept structures}

The developed concept consists of:

1. Analyses, research and application development pre-work.

2. The aim of the application.

3. Short description of application idea in several steps:
a. Target groups,
b. Get information about the users or the target group,
c. Analyse of the information,
d. Provide advice for formatting, 
e. E-material formatting option,

f. Feedback.

4. What the application should do:

a. Get basic user information,

b. Get additional users' information,

c. Get basic information about the target group,

d. Made user and/or target group information analyses,

e. Provide possible advice for formatting, based on analyses,

f. Made e-material formatting by advice,

g. Possibility to cancel or make changes in advised formatting,

h. Additional formatting tools, if a user wants to do it manually or in addition,

5. How the application should work:
a. Fast and qualitatively.
b. Get information and make analyse.
c. Suggest formatting advice.
d. Make the formatting for e-materials and text.
e. The app should be easy to use from the regular users' side.
f. Need to be possible format popular document formats - word, pdf, excel, etc.

6. Database:
a. Users profiles,
b. Users answers,
c. Analysing scheme,
d. Suggested advices for e-material formatting,
e. User choice,
f. Data about users' comfort responses after use of suggested formatting.

7. Interface, design, architecture
a. The app visually must look simple but professional at the same time, and text must be easy to percept,
b. Must have an individual user profile and login,
c. User information,
d. During the analysis, there should be a statement that analysis is being made,
e. A suggestion window with a visual example of the proposed formatting format,
f. The user can cancel and not use advised format and use original without changes,
g. Possibility to save advised format,
h. Button for additional formatting,
i. Assessment of subjective feelings.

8. Description of the case:
a. Opening the app,
b. Registration,
c. Authorization,
d. The questionnaire,
e. Analyzation,
f. Change approvement,
g. E-material formatting,
h. Document opening,
i. Uploading,
j. Create your own criteria,
k. Make changes, 
1. Save changes,

m. Rate the formatting and give feedback,

n. Save formatting for future use,

o. Cancelation (full or partly).

9. Researchers side:

a. Access to database data,

b. Possibility to change recommendations for e-material formatting

\subsection{More detailed concept description}

1. Analyses, research and application development pre-work

a. Literature research and analyses - publication have been made [15]

b. Statistical data analyses both worldwide and local - publication have been made [16; 17]

c. Users need research and analyses - publication have been made $[16 ; 18 ; 19]$

d. Users preferences research and analyses - publication have been made $[16 ; 19 ; 20]$

e. Patient data research and analyses - publication have been made [17]

f. Related programs, applications, and tools analyses - master thesis [14] and some student course work

g. Development of recommendations for e-material formatting - recommendations developed, and publication have been made [15 - 20]

h. The scheme of answers analyses - in progress.

For more detailed and more accurate data and recommendations, researches are still in progress and recommendations are updated regularly.

2. The aim of the application is to make e-material textual information formatting in the e-study environment (for the prototype designed for MOODLE type environment with a possibility to adapt) according to the recommendations which are developed to improve the comfort of using e-material in learning and study process and decrease near work load by adapting on individual needs.

3.Short description of application idea and development and working stages in several main steps

a. Target groups - for whom app is intended to work and who will use it use (at least 3 main age groups for basic formatting advice)

b. Get information about users and/or target group in the registration form and the short questionnaire

c. Analyse of registered user information (following previously prepared scheme according to users' answers: give advice according to each answer and related step in the scheme)

d. Provide advice for formatting (after all step-by-step analysing have been done)

e. E-material formatting option (application provides e-material formatting by provided advice based on recommendations)

f. Feedback (the user can rate the satisfaction of advised text format and/or leave a comment about it.).

4. What normally working application should do

a. Get basic user information like age, gender, work or education scope, vision problems or refraction 
correction - for all users who want to use the app for text document formatting

b. If the user wants more individual advice, get additional users' information - about reading and learning difficulties and complains, vision problems or eye diseases, specific working conditions, working distance, working screen size, and other related information, other health conditions or diagnoses, etc.

c. Get basic information about target group - for e-material creators, can be changeable for each material, can save template forms

d. Made the user and/or the target group information analyses (followed by the scheme: question answer - related to target group - related to recommendation points in the scheme - advice)

e. Provide possible advice for formatting, based on analyses (the user can choose to use them or not)

f. Create a document with new e-material formatting by advice. It is related to the following parameters: font type, font size, line spacing, text and background colour (other formatting parameters can be added also).

g. Have the possibility to cancel or make changes in advised formatting parameters

h. Additional formatting tools, if the user wants to do it manually or in addition (zoom - mostly for non-formatted parts of the document as graphs and images, must provide a high quality of magnification; colour masks - for text and background contrast increasing in special conditions; or other needed tools).

5. The application should work fast and qualitatively without program bugs and errors in all stages - in information collecting, analysation process, saving, responding, e-material formatting and document creating. It must follow all steps correctly and accurately. The application must be easy to use from the regular users' side without additional training. There is a need to be possible to recognise and format popular document formats as word, pdf, excel, etc. The application would be very valuable in case if could be a possibility to format graphs, tables, and images.

6. Data base must save all needing information about the users - personal information, given answers; analysing scheme and adaptation; suggested advice for e-material formatting after analyse and what users prefer (ask the question about a need to use the choice that was used in the previous connection session) or what changes made manually; feedbacks as data about users' comfort responses after use of suggested formatting - survey-generated questions after experience of using new text formatting- short and easy answered, not taking too much users time.

7. Interface, design, architecture must contain as much specific information as possible.

a. The app interface must look simple but professional at the same time, and easy to percept, it must be designed by related e-material formatting.

b. Must have an individual user profile and login

c. User information - survey-generated questions - short and easy answered, not taking too much users time, provided in two options: The first, regular questioner for all the users, very short for basic information. The second, optional questioner for whom want more individualized advice.

d. During the analysis, there should be a statement that analysis is being made (can be some moving image with text, showing how time analysis will take) 
e. A suggestion window with a visual example of the proposed formatting format, as text will look like, if new formatting applied, must appear on one side of the page. Next it, on the other side, should be shown non-formatted sample of text from the original document.

f. The user can cancel and not use advised format and use original document format without any changes.

g. Possibility to save advised format with or without manual changes.

h. Button for additional formatting.

i. At the end of the work - assessment of subjective feelings (to be written and executed shortly).

For easier perception of idea and construction of application should add schematic drawings and visual images in the concept.

8. Description of the case to each step of application functions has described by using the sample what is shown in table 1.

Table 1. Sample for Description of the case step one - registration

\begin{tabular}{|c|c|c|c|}
\hline 1. & Name & \multicolumn{2}{|r|}{ Registration } \\
\hline 2. & $\begin{array}{c}\text { Action } \\
\text { performer: }\end{array}$ & \multicolumn{2}{|c|}{ User: student, professor, lecturer, etc. } \\
\hline 3. & Purpose: & \multicolumn{2}{|c|}{$\begin{array}{l}\text { To be able to use a formatting app, the user at the } \\
\text { first needs to create a personal profile, including } \\
\text { some personal information (what make a difference } \\
\text { for formatting advice) }\end{array}$} \\
\hline 4. & Conditions: & \multicolumn{2}{|c|}{$\begin{array}{l}\text { User must have internet access, email address } \\
\text { and/or account in MOODLE }\end{array}$} \\
\hline 5. & \multicolumn{3}{|c|}{ Short description: } \\
\hline & \multicolumn{3}{|c|}{$\begin{array}{l}\text { When you enter web page http: // ... press the "Register" button and } \\
\text { enter the data: a name, surname, e-mail address, create a password. } \\
\text { Specify specific data about yourself: gender, age, need or not glasses } \\
\text { for computer work, etc. }\end{array}$} \\
\hline 6. & $\begin{array}{c}\text { Related use } \\
\text { cases: }\end{array}$ & \multicolumn{2}{|c|}{ Renew registration or user's information } \\
\hline 7. & \multicolumn{3}{|c|}{ Typical sequence of events: } \\
\hline & Action o & erformer & System reaction \\
\hline & $\begin{array}{r}\text { 1. Open the we } \\
\text { 3. Click } \\
\text { 5. Type in "Na } \\
\text { "E-mail Addre } \\
\text { "Repeat Passu } \\
\text { "Age", or "Ye } \\
\text { 7. Click } \\
\text { 9a. nothing as } \\
\text { 9b. repeat step } \\
\text { or }\end{array}$ & $\begin{array}{l}\text { oge http: // .... } \\
\text { egister" } \\
\text { ", "Surname", } \\
\text { ', "Password", } \\
\text { d", "Gender", } \\
\text { "No" and so } \\
\text { egister" } \\
\text { sponse on 8a } \\
\text { 8. as response } \\
\text { b }\end{array}$ & $\begin{array}{l}\text { 2. The page opens } \\
\text { 4. Open the registration form } \\
\text { 6. The user fills in the data } \\
\text { 8a. System shows "User } \\
\text { registration successful" } \\
\text { 8b. System displays "Registration } \\
\text { failed, check input data" } \\
\text { 10. registration done }\end{array}$ \\
\hline 8. & \multicolumn{3}{|c|}{ Post-conditions: } \\
\hline
\end{tabular}


The home page opens and the system switches to standby mode

9. Researchers side gives access to all data in the application database. Access to such database data as:

a. Getting feedback information from users' satisfaction of used text formatting

b. Getting information about most used formatting

c. Getting information about most usable formatting

d. Getting information about users (relevant to research).

Possibility to adapt recommendations for e-material formatting advice after app user testing and feedback and information research - application "learning" process.

\section{Conclusion}

The concept includes all application sides - ideas, information, involved persons as developers and users, technical solutions and visual design. For easily understandable idea and final application prototype, the concept must be as much detailed and specific as possible. The full concept gives all necessary information for developers and an insight into the final product -application. It describes how application would work stepby-step to reach the main goal - e-material formatting. The concept is an important part of application designing and programming.

As a reasonable next step, research on the possible technical solution for making application prototype has been done in addition by technical side based on developed application concept.

A future step is to develop an application prototype by starting coding. The prototype of the application is in need to create to test and analyses users and user needs, offer the best possible e-material formatting and brings it to life. It is the next part of the research.

\section{References}

[1] D.O. Mutti, G.L. Mitchell, M.L. Moeschberger, L.A. Jones, K. Zadnik, "Parental Myopia, Near Work, School Achievement, and Children's Refractive Error," Invest Ophthalmol Vis Sci., vol.43(12):3633-40, Dec 2002.

[2] S.M. Saw, F.J. Nieto, J. Katz, O. Schein, B. Levy, S.J. Chew, "Factors Related to the Progression of Myopia in Singaporean Children," Optom Vis Sci.; vol.77(10):549-54. 2000.

[3] N. Stuart, "Myopia Research: From the Margins to the Mainstream," EyeNet Magazine, Nr. Nov. 2015

[4] K. Zadnik, W.A. Satariano, D.O. Mutti, R.I. Sholtz, A.J. Adams, "The Effect of Parental History of Myopia on Children's Eye Size," JAMA; 271(17):1323-7. 1994.

[5] Collins English Dictionary "word - close work" available online: https://www.collinsdictionary.com/dictionary/english/close-work, last visit: 28.12.2018.

[6] W. Low, M. Dirani, G. Gazzard, Y.H. Chan, H.J. Zhou, P. Selvaraj, et al., "Family history, near work, outdoor activity, and myopia in Singapore Chinese preschool children," Br J Ophthalmol. 94(8):1012-6, 2010.

[7] B. Lu, N. Congdon, X. Liu, K. Choi, D.S.C. Lam, M. Zhang, et al., "Associations Between Near Work, Outdoor Activity, and Myopia Among Adolescent Students in Rural China: The Xichang Pediatric Refractive Error Study Report No. 2," Arch Ophthalmol. 2009, 127(6):769-75. Jun 2009.

[8] M. Zhang, L. Li, L. Chen, J. Lee, J. Wu, A. Yang, et al., "Population Density and Refractive Error among Chinese Children," Invest Ophthalmol Vis Sci.;51(10):4969-76, Oct 2010.

[9] B.A. Holden, T.R. Fricke, D.R. Wilson, "Global prevalence of Myopia and High Myopia and temporal trends from 2000 through 2050," Ophthalmology, Epub, Nr. Feb.2016.

[10] H.M. Huang, D. S.T. Chang, P.C. Wu, "The Association between Near Work Activities and Myopia in Children-A Systematic Review and Meta-Analysis," Journal Plos One, Oct 2015. 
[11] Report from We Are Social and Hootsuite "Global Digital Statshot Q3 2017", available online: https://www.slideshare.net/wearesocialsg/digital-in-2017-global-overview, last visit: 28.12.2018.

[12] M. Khan, Khushdil, "Comprehensive Study on the Basis of Eye Blink, Suggesting Length of Text Line, Considering Typographical Variables the Way How to Improve Reading from Computer Screen," Advances in Internet of Things, vol. 3, no. 1.

[13] J. Nielsen, "Designing Web Usability: The Practice of Simplicity," New Riders Publishing, Indianapolis, 2000, p. 420.

[14] A. Zīverte, "Elektronisku teksta dokumentu pielāgošanas metodes," Master thesis, Liepaja University

[15] K. Mackare, A. Jansone, "Research of guidelines for designing e-study materials," Proceedings of the 11th International Scientific and Practical Conference Environment. Technology. Resources. June 15-17, 2017. Vol. 2.

[16] K. Mackare, A. Jansone, "Habits of Using internet and digital devices in education," Proceedings of the International Scientific Conference SOCIETY. INTEGRATION. EDUCATION. May 25th-26th, 2018, Volume V, May 25th-26th 2018, 348-356.

[17] K. Mackare, A. Jansone, "Digital Devices Use for Educational Reasons and Related Vision Problems," Proceedings of the 4th International Conference on Lifelong Education and Leadership, July 2-4, 2018.

[18] K. Mackare, A. Jansone, "Users' preferences of e-material formatting parameters," Proceedings of Multidisciplinary Academic Conference on Education, Teaching and Learning, Dec. 2017.

[19] K. Mackare, A. Jansone, "Recommended formatting parameters for e-study materials," IJLEL JOURNAL Vol. 4, No. 1.

[20] M. Zigunovs, K. Mackare, A. Jansone, "E-learning material adaptive software development," Baltic Journal of Modern Computing, vol. 12 (2024), No. 1, pp. 1-3. 